\title{
ANALISIS FAKTOR-FAKTOR YANG MEMPENGARUHI PRODUKSI KENTANG DI KECAMATAN TIMANG GAJAH KABUPATEN BENER MERIAH
}

\author{
Agus Fianda, Fadli dan Zuriani
}

\begin{abstract}
ABSTRAK
Kecamatan Timang Gajah adalah salah satu kecamatan yang menghasilkan produksi kentang hanya sebesar 72,50 Kwintal dengan luas lahan $5 \mathrm{Ha}$. Komoditas kentang yang dibudidayakan di Kecamatan Timang Gajah memiliki produktivitas rendah yaitu $14,50 \mathrm{Kwintal} / \mathrm{Ha}$. Rendahnya produksi kentang dipengaruhi oleh faktor-faktor produksi seperti bibit kentang yang dipakai, tenaga kerja yang digunakan, jumlah pupuk yang dipergunakan dalam proses produksi kentang. Tujuan penelitian yaitu untuk mengetahui faktor-faktor yang. mempengaruhi produksi kentang di Kecamatan Timang Gajah Kabupaten Bener Meriah. Metode analisis data dengan menggunakan fungsi produksi Cobb-Douglass. Hasil penelitian menunjukkan bahwa produksi kentang di Kecamatan Timang Gajah Kabupaten Bener Meriah dipengaruhi oleh 5 faktor yaitu luas lahan $\left(\mathrm{x}_{1}\right)$, tenaga kerja $\left(\mathrm{x}_{2}\right)$, bibit $\left(\mathrm{x}_{3}\right)$, pupuk $\left(\mathrm{x}_{4}\right)$, dan pestisida $\left(\mathrm{x}_{5}\right)$. Berdasarkan hasil regresi diperoleh bahwa secara serempak faktor-faktor produksi yaitu luas lahan, tenaga kerja, bibit, pupuk dan pestisida berpengaruh signifikan terhadap produksi kentang. Sedangkan secara parsial luas lahan, bibit dan pestisida berpengaruh signifikan terhadap produksi kentang, sedangkan tenaga kerja dan pupuk tidak berpengaruh signifikan terhadap produksi kentang di Kecamatan Timang Gajah Kabupaten Bener Meriah.
\end{abstract}

Kata kunci : Faktor produksi dan Fungsi Produksi Cobb-Douglass

\section{PENDAHULUAN}

Kentang (Solanum tuberosum

L) dapat dikembangkan karena permintaannya terus meningkat sejalan dengan pertumbuhan penduduk, sebagai bahan pangan bergizi tinggi, sebagai bahan baku industri pengolahan pangan, sebagai komoditas ekspor non migas, dan sebagai sumber pendapatan petani (Sumarno, 2013).

Kabupaten Bener Meriah merupakan salah satu kabupaten di provinsi Aceh yang memproduksi kentang.Produksi kentang di Kabupaten Bener Meriah mempunyai 
potensi dalam pengembangan

Kabupaten Bener Meriah tahun 2008 tanaman kentang.Untuk lebih jelas - 2013 dapat dilihat pada tabel 1 mengenai perkembangan kentang di berikut.

Tabel 1. Perkembangan produksi kentang di Kabupaten Bener Meriah tahun 20082013

\begin{tabular}{lr}
\hline Tahun & Produksi Kentang (Ton) \\
\hline 2008 & 15.671 \\
\hline 2009 & 12.701 \\
\hline 2010 & 5.909 \\
\hline 2011 & 4.440 \\
\hline 2012 & 2.371 \\
\hline 2013 & 81.080 \\
\hline
\end{tabular}

Sumber : BPS Provinsi Aceh, 2014

Terlihat pada tabel 1 diatas bahwa pengembangan produksi kentang di Kabupaten Bener Meriah mengalami penurunan mulai tahun 2009 yaitu 12.701 Ton dan terus mengalami penurunan produksi sampai tahun 2012 yaitu 2.376 Ton, sedangkan pada tahun 2013 produksi kentang mengalami peningkatan sebesar 81.080 Ton.

Pengembangan luas lahan kentang di Kabupaten Bener Meriah tersebar di berbagai kecamatan. Untuk lebih jelas mengenai luas lahan produksi kentang di Kabupaten Bener Meriah dapat di lihat pada tabel 2.

Tabel 2. Luas Lahan dan Produksi Kentang di Kabupaten Bener Meriah Tahun 2012

\begin{tabular}{|l|r|r|r|}
\hline \multicolumn{1}{|c|}{ Kecamatan } & \multicolumn{1}{|c|}{$\begin{array}{c}\text { Luas Lahan } \\
\text { ( Ha) }\end{array}$} & $\begin{array}{l}\text { Produksi } \\
\text { (Kwintal) }\end{array}$ & $\begin{array}{c}\text { Produktivitas } \\
\text { (Kwintal/Ha) }\end{array}$ \\
\hline Permata & 510 & $10.412,2$ & 20,42 \\
\hline Syiah Utama & 7 & 92,8 & 13,26 \\
\hline Bandar & 188 & $3.293,3$ & 17,52 \\
\hline Bukit & 395 & 7.172 & 18,16 \\
\hline Wih pesam & 67 & 2.020 & 30,15 \\
\hline Timang Gajah & 5 & 72,50 & 14,50 \\
\hline Mesidah & 16 & 383,7 & 23,98 \\
\hline Bener Kalipah & 12 & 269,5 & 22,46 \\
\hline Jumlah & $\mathbf{1 . 2 0 0}$ & $\mathbf{2 3 . 7 1 6}$ & $\mathbf{1 9 , 7 6}$ \\
\hline
\end{tabular}

Sumber : Bener meriah dalam Angka 2012 
Berdasarkan tabel 2 terlihat bahwa dari 10 kecamatan yang ada di Kabupaten Bener Meriah terdapat 8

kecamatan yang menghasilkan kentang yaitu Kecamatan Permata, Kecamatan Syiah Utama, Kecamatan Bandar, Kecamatan Bukit, Kecamatan Wih Pesam, Kecamatan Timah Gajah, Kecamatan Mesidah, Kecamatan Bener Kalipah.

Kecamatan Timang Gajah adalah salah satu kecamatan yang menghasilkan produksi kentang hanya sebesar 72,50 Kwintal dengan luas lahan 5 Ha. Komoditas kentang yang dibudidayakan di kecamatan Timang Gajahmemiliki produktivitas rendah yaitu 14,50 Kwintal/Ha. Rendahnya produksi kentang dipengaruhi oleh faktor-faktor produksi seperti bibit kentang yang di pakai,tenaga kerja yang digunakan, jumlah pupuk yang dipergunakan dalam proses produksi kentang (Kasimin, 2014).

Penelitian ini bertujuan untuk mengetahui faktor-faktor yang mempengaruhi produksi kentang di Kecamatan Timang Gajah Kabupaten Bener Meriah.

\section{METODE PENELITIAN}

Penelitian ini dilakukan di Kecamatan Timang Gajah Kabupaten Bener Meriah. Kecamatan Timang Gajah merupakan salah satu penghasil kentang di Kabupaten Bener Meriah. Kecamatan Timang Gajah memiliki 30 desa, kemudian dipilih 2 desa yaitu Desa Pandan Pediangan dan Desa Bukit Mulie dengan pertimbangan karena hanya keduadesa tersebut yang membudidayakan tanaman kentang. Objek Penelitian yaitu petani yang melakukan usahatani kentang di Desa Pandan Pediangan dan Desa Bukit Mulie. Ruang lingkup penelitian ini adalah menganalisis faktor-faktor yang mempengaruhi produksi kentang di Kecamatan Timang Gajah Kabupaten Bener Meriah.

Populasi dalam penelitian ini adalah petani yang membudidayakan kentang di Desa Pandan Pediangan dan Desa Bukit Mulie. Pengambilan Sampel di lakukan dengan menggunakan metode sensus yang artinya semua individu (petani) yang ada dalam populasi sebagai responden yang diselidiki atau 
diwawancarai. Seluruh populasi dalam penelitian yaitu sebanyak 21 orang dijadikan sampel.

Metode yang digunakan dalam penelitian ini untuk menganalisis faktor-faktor yang mempengaruhi produksi kentang di Kecamatan Timang Gajah Kabupaten Bener Meriah Provinsi Aceh adalah model fungsi produksi CobbDouglas dengan menggunakan metode Ordinary Least Square (OLS) yaitu metode yang digunakan untuk mengetahui besarnya pengaruh perubahan dari suatu variable independen terhadap variabel dependen (Gujarati \& Porter, 2003).

1. Fungsi Cobb-Douglass

Menurut Soekartawi (2003) fungsi produksi Cobb-Douglass secara umum dapat tulis sebagai berikut:

$$
\begin{aligned}
& \mathrm{Y}=\mathrm{a} \quad \mathrm{X} 1^{\mathrm{b} 1} \mathrm{X} 2^{\mathrm{b} 2} \quad \mathrm{X} 3^{\mathrm{b} 3} \\
& \mathrm{X} 4^{\mathrm{b} 4} \ldots \ldots \ldots \mathrm{X}_{\mathrm{n}} \ldots \ldots \mathrm{e}
\end{aligned}
$$

Untuk mempermudahkan perhitungan, fungsi tersebut kemudian diubah dalam bentuk logaritma, sehingga persamaan matematisnya menjadi

$$
\begin{aligned}
\operatorname{Ln} Y= & \ln \mathrm{a}+\ln \mathrm{X}_{1}+\ln \mathrm{X}_{2}+\ln \mathrm{X}_{3}+ \\
& \ln \mathrm{X}_{4}+\ln \mathrm{X}_{5} \ldots+\mathrm{e}
\end{aligned}
$$

Keterangan:

$$
\begin{array}{ll}
\mathrm{Y} & =\text { Produksi }(\mathrm{Kg}) \\
\mathrm{X}_{1} & =\text { Luas Lahan }(\mathrm{Ha}) \\
\mathrm{X}_{2} & =\text { Tenaga Kerja }(\mathrm{HOK}) \\
\mathrm{X}_{3} & =\text { Bibit }(\mathrm{Kg}) \\
\mathrm{X}_{4} & =\text { Pupuk }(\mathrm{Kg}) \\
\mathrm{X}_{5} & =\text { Pestisida }(\mathrm{liter}) \\
\mathrm{a} & =\text { Konstanta } \\
\mathrm{e} & =\text { Error Term }
\end{array}
$$

2. Uji Asumsi Klasik
a) Uji Normalitas

Menurut Santoso (2001) menyatakan bahwa suatu data dikatakan distribusi normal apabila penyebaran data pada grafik normal P-P Plot Resgresion Standardized Residual mengikuti garis diagonal.

b) Uji Multikolinieritas

Untuk mendeteksi ada atau tidaknya multikolinieritas dalam regresi dilakukan dengan melihat nilai tolerance yaitu tidak boleh kurang dari 0,10 dan nilai VIF (Variance Inflation Factor) tidak 
boleh lebih dari 10. Jika VIF lebih besar dari 10, dalam data maka terdapat mulitikolinielitas yang

sangat tinggi (Ghozali, 2005). c) Uji Heteroskedastisitas

Uji heteroskedastisitas bertujuan menguji apakah dalam model regresi terjadi ketidaksamaan varince dari residual satu pengamatan ke pengamatan lainnya. Jika varian satu pengamatan ke pengamatan yang lain tetap, maka disebut homoskedastisitas dan jika berbeda disebut heteroskedastisitas. Model regresi yang baik adalah homoskedatisitas atau tidak terjadi heteroskedastisitas (Kasimin, 2014)

\section{Uji Statistik}

a) Koefisien Korelasi (R)

Koefisien Korelasi

dimaksudkan untuk melihat bagaimana hubungan antara variabel bebas dengan variabel terikat. Koefisien korelasi di pergunakan untuk mengukur kekuatan hubungan 2 variabel dan juga untuk mengetahui bentuk hubungan antara 2 variabel. b) Koefisien Determinasi

Koefisien determinasi $\left(\mathrm{R}^{2}\right)$ menunjukkan besarnya keragaman semua variabel independen yang dapat menjelaskan keragaman variabel dependen. Koefisien determinasi dapat dirumuskan sebagai berikut:

$$
\mathrm{R}^{2}=1-\frac{\sum \hat{\mathrm{u}}_{\mathrm{i}^{2}}}{\sum \hat{\mathrm{y}}_{\mathrm{i}^{2}}}
$$

c) Uji Slimultan (Uji F)

Uji simultan (Uji F-statistik) bertujuan untuk mengetahui apakah semua variabel independen dalam model secara bersama-sama memiliki pengaruh yang nyata terhadap variabel dependen yang diteliti. Pengujian simultan (uji F) dilakukan dengan melihat nilai signifikansi sebagai berikut:

- Jika nilai Sig. < 0.05 maka semua variabel bebas secara bersamasama berpengaruh signifikan terhadap variabel terikat.

- Jika nilai Sig. > 0.05 maka semua variabel bebas secara bersamasama tidak berpengaruh signifikan terhadap variabel terikat. 
d) Uji Parsial (Uji t)

Uji t digunakan untuk melihat pengaruh variabel independen terhadap variabel dependen secara individual, dengan kriteria pengujian berdasarkan nilai signifikansi :

- Jika nilai Sig. < 0,05 maka variabel bebas berpengaruh signifikan terhadap variabel terikat

- Jika nilai Sig. > 0,05 maka variabel bebas tidak berpengaruh signifikan terhadap variabel terikat

\section{HASIL DAN PEMBAHASAN}

\section{Penggunaan}

Faktor-Faktor

\section{Produksi}

Penggunaan faktor - faktor produksi dalam penelitian ini meliputi luas lahan, tenaga kerja, pupuk, bibit dan pestisida.

\section{Luas Lahan}

Petani kentang di daerah penelitian, umumnya petani menanam tanaman kentang pada lahan milik sendiri, hanya 6 orang dari 21 sampel yang menanam pada lahan sewa.
Rata-rata harga sewa lahan untuk satu kali produksi didaerah penelitian yaitu Rp 600.000. Luas lahan yang digunakan tiap petani untuk usahatani kentang di lokasi penelitian cukup beragam yaitu dari $0,12 \mathrm{Ha}$ hingga 0,36 Ha.

\section{Tenaga Kerja}

Di daerah penelitian tenaga kerja ada yang berasal dari dalam keluarga dan ada yang dari luar keluarga. Jumlah penggunaan tenaga kerja didaerah penelitian sebanyak 1293,75 HOK dengan luas lahan sebesar $5 \mathrm{Ha}$ dan rata-rata penggunaan tenaga kerja sebanyak 61,61HOK/Ha, karena tenaga kerja dihitung dengan hari orang kerja (HOK).

\section{Bibit}

Petani kentang di daerah penelitian umumnya menggunakan bibit kentang dari hasil produksi sebelumnya.Jumlah penggunaan bibit di daerah penelitian sebanyak 4950 Kg dengan luas lahan $5 \mathrm{Ha}$.

\section{Pupuk}

Petani kentang didaerah penelitian memberikan pupuk ZA seminggu setelah penanaman, 
kemudian diberikan pupuk TsP dan KcL pada saat kentang berumur 30-40 hari setelah tanam. Pupuk NPK diberikan saat umur kentang 70-80

\section{8}

mancet diberikan pada saat seminggu setelah tanam sedangkan mbleser diberikan pada saat umur kentang 70 hari setelah tanam. Jumlah penggunaan pestisida ditempat penelitian adalah sebanyak 54,6 liter dengan luas lahan $5 \mathrm{Ha}$ dan rataratanya 2,6 liter/Ha.

\section{Uji Asumsi Klasik}

\section{a. Pengujian Normalitas}

Dari hasil data yang didapatkan bahwa hasil output data - data dalam model regresi, variabel terikat (dependen) dan variabel bebas (independen) memiliki distribusi normal, karena penyebaran data pada grafik normal P-P Plot Regression Standardized Residual mengikuti garis normal.

Normal P-P Plot of Regression Standardized Residual

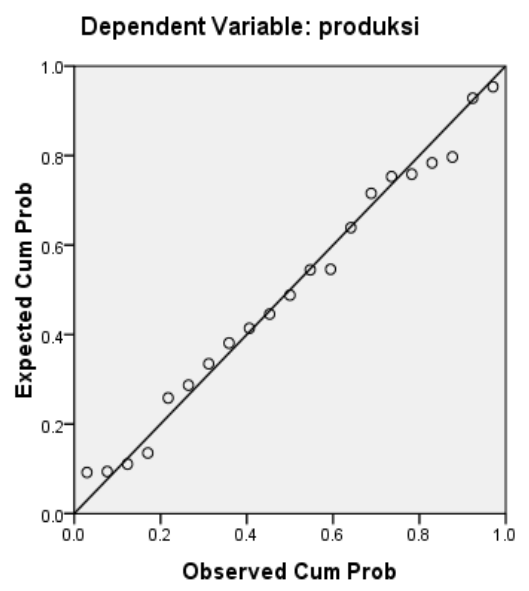




\section{b. Uji Multikolinearitas}

Dari hasil output data didapatkan bahwa variabel luas lahan, tenaga kerja, bibit, pupuk, dan pestisida memiliki nilai VIF $<10$ dan nilai Tolerance $>0,10$, berarti tidak terjadi multikolinearitas. Maka dapat disimpulkan bahwa antar variabel luas lahan, bibit, pupuk, pestisida, dan tenaga kerja tidak terjadi korelasi sempurna, sehingga

uji multikolinearitas telah terpenuhi. Hal ini dapat dilihat pada Tabel berikut:

Tabel 3. Hasil Uji Asumsi Multikolinieritas

\begin{tabular}{lccl}
\hline \multirow{2}{*}{ Variabel } & \multicolumn{2}{c}{ Collinearity Statistic } & \multirow{2}{*}{ Keterangan } \\
\cline { 2 - 3 } & Tolerance & VIF & \\
\hline Luas Lahan & .574 & 1.742 & Non Multikolinearitas \\
\hline Tenaga Kerja & .858 & 1.166 & Non Multikolinearitas \\
\hline Bibit & .636 & 1.571 & Non Multikolinearitas \\
\hline Pupuk & .774 & 1.293 & Non Multikolinearitas \\
\hline Pestisida & .587 & 1.705 & Non Multikolinearitas \\
\hline
\end{tabular}

Sumber : Data primer, 2016 (diolah)

\section{c. Uji Heteroskedastisitas}

Hasil output data SPSS grafik scatterplot menunjukkan bahwa residual data tidak terdapat pola yang jelas dari titik menyebar di atas dan di bawah angka 0 pada sumbu $Y$, dengan begitu dipastikan tidak terjadi heterokedastisitas.

Scatterplot

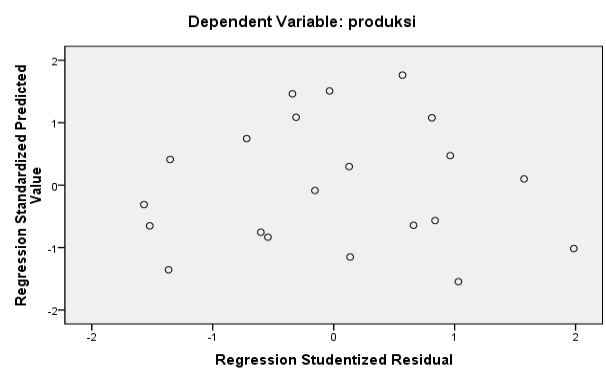

\section{Uji Statistik}

Uji statistik dimaksudkan untuk melihat hubungan dan pengaruh variabel bebas terhadap variabel terikat yaitu produksi kentang. Adapun uji statistik dalam penelitian ini yaitu

\section{a. Koefisien Korelasi (R)}

Koefisien Korelasi dimaksudkan untuk melihat bagaimana hubungan antara variabel bebas dengan variabel terikat. Dari hasil analisis dapat dilihat bahwa 
koefisien korelasi (R) sebesar 0,891

yang artinya variabel bebas yaitu luas

lahan, tenaga kerja, bibit, pupuk dan

\section{0}

pestisida berhubungan sangat kuat dengan variabel terikat yaitu produksi kentang.

\section{b. Koefisien Determinasi ( $\mathbf{R}^{\mathbf{2}}$ )}

Hasil analisis menunjukkan bahwa nilai koefisien determinasi $\left(\mathrm{R}^{2}\right)$ adalah 0,794 yang berarti $79,4 \%$ luas lahan,tenaga kerja, bibit, pupuk dan pestisida mampu menjelaskan produksi kentang, dan sisanya 20,6\% diterangkan oleh variabel lain diluar model. Variabel lain yang mempengaruhi produksi kentang yaitu curah hujan dan suhu.

\section{c. Pengujian Secara Simultan (Uji F)}

Hasil pengujian uji $\mathrm{F}$ didapatkan nilai Sig. F sebesar 0,000 yang berarti $0,000<0,05$. Dengan demikian berarti secara bersamasama luas lahan, tenaga kerja, bibit, pupuk dan pestisida berpengaruh signifikan terhadap produksi kentang.

\section{d. Pengujian Secara Parsial (Uji T)}

Uji parsial (uji t) dilakukan untuk memprediksi apakah masingmasing dari variabel bebas yaitu luas lahan, tenaga kerja, bibit, pupuk dan pestisida berpengaruh signifikan atau tidak signifikan terhadap produksi kentang. Pengujian signifikan pada penelitian ini diuji pada taraf $5 \%$. Untuk lebih jelasnya dapat dilihat pada tabel berikut: 
Tabel 4. Analisis Regresi Pendugaan Faktor-faktor yang Mempengaruhi Produksi Kentang

\begin{tabular}{|c|c|c|c|c|c|c|c|}
\hline \multirow[t]{2}{*}{ Model } & \multicolumn{2}{|c|}{$\begin{array}{l}\text { Unstandardized } \\
\text { Coefficients }\end{array}$} & \multirow{2}{*}{$\begin{array}{l}\text { Standardized } \\
\text { Coefficients } \\
\text { Beta }\end{array}$} & & \multirow[t]{2}{*}{ Sig. } & \multicolumn{2}{|c|}{ Collinearity Statistics } \\
\hline & $\bar{B}$ & Std. Error & & & & Tolerance & VIF \\
\hline (Constant) & -1.791 & 1.941 & & -.923 & .371 & & \\
\hline Luas Lahan & .245 & .111 & .340 & 2.201 & .043 & .574 & 1.742 \\
\hline Tenaga Kerja & .517 & .384 & .170 & 1.347 & .198 & .858 & 1.166 \\
\hline Bibit & 1.027 & .160 & .941 & 6.412 & .000 & .636 & 1.571 \\
\hline Pupuk & .103 & .097 & .141 & 1.057 & .307 & .774 & 1.293 \\
\hline Pestisida & -.180 & .084 & -.328 & -2.145 & .049 & .587 & 1.705 \\
\hline $\begin{array}{l}\mathrm{R}=0.891 \\
\mathrm{R}^{2}=0.794\end{array}$ & & $\begin{array}{l}\text { Adjust } \mathrm{R} \\
\mathrm{F} \text { sig = }\end{array}$ & $\begin{array}{l}R^{2}=0.726 \\
0.000\end{array}$ & & $=11$. & & \\
\hline
\end{tabular}

Sumber: Data primer, 2016 (diolah)

Dari tabel hasil regresi di atas maka persamaan fungsi produksi adalah sebagai berikut:

\section{$\operatorname{LnY}=-1.791+0.245 \operatorname{LnX} 1+0.517$ $\mathrm{LnX}_{2}+1.027 \mathrm{LnX}_{3}+\mathbf{0 . 1 0 3}$ \\ $\operatorname{LnX}_{4}$ - 0.180 LnX + e}

Secara parsial luas lahan $\left(\mathrm{X}_{1}\right)$ berpengaruh signifikan terhadap produksi kentang. Hal ini dapat dilihat dari nilai probabilitas signifikan yaitu 0.043 lebih kecil dari derajat kepercayaan $(\alpha=0.05)$. Koefisien regresi luas lahan $\left(\mathrm{X}_{1}\right)$ sebesar 0.245 yang berarti bahwa setiap penambahan luas lahan sebesar $1 \%$ maka dapat meningkatkan produksi kentang sebesar $0.245 \%$, karena semakin luas lahan yang digarap petani maka produksi yang dihasilkan semakin banyak, dengan asumsi cateris paribus artinya faktor selain luas lahan dianggap tetap.

Secara parsial tenaga kerja $\left(\mathrm{X}_{2}\right)$ tidak berpengaruh signifikan terhadap produksi kentang, hal ini ditunjukkan oleh nilai probabilitas signifikan 0,198 lebih besar dari alpha $(0,05)$. Jumlah penggunaan tenaga kerja rata-rata adalah sebanyak 61,61 HOK/ha. Nilai koefisien regresi tenaga kerja adalah 0.517 berarti jika terjadi penambahan tenaga kerja sebanyak $1 \%$ maka akan meningkatkan produksi kentang sebanyak $0.517 \%$.

Nilai koefisien regresi bibit adalah 1.027 yang berarti jika terjadi penambahan bibit sebesar $1 \%$ maka 
akan meningkatkan produksi kentang sebanyak $1.027 \%$. Secara parsial penggunaan bibit $\left(\mathrm{X}_{3}\right)$ berpengaruh signifikan terhadap produksi kentang, hal ini ditunjukkan oleh nilai probabilitas signifikan 0.00 lebih kecil dari alpha (0.01). Jumlah penggunaan bibit sebanyak $4.950 \mathrm{~kg}$ dengan luas lahan $5 \mathrm{Ha}$.

Dari hasil analisis secara parsial pupuk $\left(\mathrm{X}_{3}\right)$ tidak berpengaruh signifikan terhadap produksi kentang. Hal ini dapat dilihat dari nilai probabilitas signifikan (0.307) lebih besar dari alpha (0.05). Nilai koefisien regresi pupuk yaitu 0.103 yang berarti bahwa setiap penambahan pupuk sebanyak $1 \%$ akan menurunkan produksi kentang sebanyak $0.103 \%$. Penggunaan pupuk ideal untuk luas lahan 1 ha yaitu sebanyak $900 \mathrm{Kg}$.

Penggunaan pestisida di tempat penelitian adalah sebanyak 54,6 liter dengan luas lahan sebesar 5 ha dengan rata-rata 2,6 liter/ha. Penggunaan pestisida tidak berpengaruh terhadap tingginya luas lahan, akan tetapi berpengaruh terhadap sedikit atau banyaknya serangan hama pada tanaman kentang sehingga berpengaruh juga terhadap laju kehilangan produksi. Secara parsial variabel pestisida berpengaruh signifikan terhadap produksi kentang, hal ini dapat dilihat dari nilai probabilitas signifikan yaitu 0.049 lebih kecil dari nilai apha $(0,05)$. Nilai koefisien regresi variabel pestisida adalah -0.180 yang berarti bahwa setiap penambahan pestisida sebanyak $1 \%$ maka akan menurunkan produksi kentang sebanyak $0.180 \%$. Hal ini menunjukkan bahwa petani yang banyak menggunakan pestisida karena serangan hama yang tinggi memperoleh produksi kentang yang lebih sedikit.

\section{KESIMPULAN}

Berdasarkan hasil regresi diperoleh bahwa secara serempak yang berpengaruh signifikan terhadap produksi kentang yaitu luaslahan $\left(\mathrm{X}_{1}\right)$, tenaga kerja $\left(\mathrm{X}_{2}\right)$, bibit $\left(\mathrm{X}_{3}\right)$, pupuk $\left(\mathrm{X}_{4}\right)$ dan pestisida $\left(\mathrm{X}_{5}\right)$, dapat dilihat dari nilai probabilitas F sebesar $(0,000)$ lebih kecil dari alpha $(0,05)$.Secara parsial luas lahan $\left(\mathrm{X}_{1}\right)$, bibit $\left(\mathrm{X}_{3}\right)$ dan pestisida $\left(\mathrm{X}_{5}\right)$ berpengaruh signifikan terhadap 
produksi kentang, sedangkan tenaga kerja $\left(\mathrm{X}_{2}\right)$, pupuk $\left(\mathrm{X}_{4}\right)$ tidak berpengaruh signifikan terhadap produksi kentang karena nilai probabilitas lebih besar dari tingkat kepercayaan (alpha).

\section{SARAN}

\begin{abstract}
Diharapkan kepada petani agar memperluas lahan untuk melakukan usahatani kentang dan juga menambah penggunaan bibit, menambah penggunaan pupuk serta meningkatkan penggunaan input agar produksi lebih maksimal.
\end{abstract}

\section{DAFTAR PUSTAKA}

BPS Provinsi Aceh. (2014). Perkembangan produksi kentang di Kabupaten Bener Meriah tahun 2008-2013e.

Ghozali, I. (2005). Aplikasi analisis multivariate dengan program SPSS. Semarang: Badan Penerbit Universitas Diponegoro.

Gujarati, D., \& Porter, D. (2003). Multicollinearity: What happens if the regressors are correlated.

Basic

Econometrics, 363.

Kasimin, S. (2014). Keterkaitan produk dan pelaku dalam pengembangan agribisnis hortikultura unggulan di Provinsi Aceh. Jurnal
Manajemen \& Agribisnis, 10(2), 117-127.

Santoso, S. (2001). Statistik nonparametrik. Elex Media Komputindo.

Sumarno, S. (2013). Isolasi amilosa dan Amilopektin dari pati kentang. Jurnal Teknologi Kimia Dan Industri, 2(2), 5762. 